\title{
LA CONCLUSIÓN ESCÉPTICA DE LA TEORÍA HUMEANA DEL MUNDO EXTERIOR*
}

SAMUEL MONDER Consejo Nacional de Investigaciones Cientificas y Técnicas Argentina

Resulta difícil evaluar el alcance que Hume atribuye a los argumentos escépticos que expone en su teoría del mundo externo. Por una parte, parece convencido de que éstos muestran la falsedad de la creencia del sentido común en objetos continuos e independientes de la percepción; pero, por otra parte, señala que los argumentos escépticos resultan incapaces de modificar nuestra adhesión a esta creencia. Desde el comienzo mismo de la investigación observa que "es inútil que nos preguntemos si hay o no hay cuerpos" (T 187). ${ }^{1}$

La interpretación usual de esta tensión consiste en señalar que, de acuerdo con Hume, la mente ha sido determinada por la naturaleza a creer en objetos exteriores y esta circunstancia no puede ser modificada mediante argumentación alguna, ya que "la creencia es

\footnotetext{
- Eate trabajo es una veraión ampliada de una comunicación lef́da en el Congreno Internacional Extraordinario de Filosofia, Córdoba (Argentina), 1987.

1 El número que sigue a la letra " $T$ " corresponde al número de página de la edición de Selby-Bigge (A Treatise of Human Nature, Oxford, Clarendon Preas, 1888). Para las citas he tomado la traducción de Félix Duque (Madrid, Editora Nacional, 1981).
} 
más propiamente un acto de la parte sensitiva de nuestra naturaleza que de la cogitativa" ( $T$ 183).

Si bien creo que esto recoge un aspecto importante de la respuesta de Hume al problema, creo también que no da cuenta de todo lo involucrado en la cuestión y que en esta explicación quedan fuera algunos elementos importantes de la teoría humeana del mundo exterior.

Un punto importante es cómo entender la imposibilidad que señala Hume de modificar nuestra adhesión a la tesis del sentido común. Esta imposibilidad bien puede deberse, como señala la interpretación estándar, a una simple cuestión de hecho: una imposibilidad psicológica dispuesta por la sabia naturaleza que no permite que abandonemos creencias indispensables para nuestra supervivencia. Pero también puede deberse a una imposibilidad debida a razones de orden lógico. ${ }^{2}$ Creo que pueden señalarse algunos elementos en la teoría de Hume que nos permiten pensar que esto es así. En este trabajo desarrollaré una interpretación de la conclusión escéptica de la teoría humeana del mundo exterior en la que se tienen en cuenta muy especialmente estos elementos. El plan es el siguiente: a continuación analizaremos la estructura general de la argumentación escéptica que expone Hume; luego, propondremos una interpretación de la tensión señalada al comienzo.

Hụme parece advertir que la cuestión de qué sea aquello que es tomado como dato de los sentidos, depende del sistema que empleamos para dar cuenta de nuestra experiencia. En este sentido, distingue dos sistemas: el vulgar y el filosófico. En el sistema vulgar, nuestras

2 Este es un punto de vista que ha sido muy poco tomado en cuenta por los intérpretes de Hume. Para una reciente interpretación en este sentido, vease D. W. Livingston, Hume's Philosophy of Common Life, Chicago y Londres, The Univeritity of Chicago Press, 1984, Cap. 1 . 
percepciones son interpretadas según el canon de los objetos públicos. En este contexto, Hume asume que

...hay una sola existencia a la que llamaré indiferentemente objeto o percepeión según convenga a mis mejores propositos; además, entenderé por estos términos lo que cualquier hombre común entiende por sombrero, sapato, piedra, o cualquier otra impresión transmitida por los sentidos (T 202).

Aunque Hume conserva como filósofo un léxico técnico y continúa hablando de "percepciones", nos advierte acerca de una asimilación, en el contexto de su análisis del sistema vulgar, de su terminología filosófica a la gramática ordinaria de términos tales como 'sombrero', 'zapato' y 'piedra', es decir, a la gramática ordinaria acerca de objetos públicos.

No debe sorprendernos que Hume hable en este contexto de "percepciones no percibidas" sin que esto resulte un sinsentido. Del mismo modo que 'percepción' se asimila a la gramática de 'objeto', se asume para 'percibir' la gramática corriente de 'ver', donde lo que se ve, se admite, no depende para su existencia del ser visto. Así, las percepciones se "ausentan" de la mente sin que resulten aniquiladas y los objetos se nos presentan "sin que exista ninguna nueva creación de una percepción o imagen" (cfr. T 207). ${ }^{3}$

El sistema filosófico, por su parte, hace su aparición como reflexión crítica acerca del sistema vulgar. Esta crítica constituye al mismo tiempo el primer paso en

- Expresiones como estas son las que han llevado recientemente a algunos intérpretes a rechasar el punto de vista ortodoxo - privatiataque arimila las percepcionea a imágenes mentales. Según W. Davie, por ejemplo, "percepciones son las cosas que conocemos, tanto las privadas como las públicas" (cfr. W. Davie, "Perceptions and Persona", en Hume Studies X, 2, nov. 1984, p. 130). A. Flew, conoiderado como exponente paradigmático de la ortodoxia, ha replicado a Davie en "Impressions and Experiences: Public or Private?" (en Hume Studies XI, 2, nov. 1985), donde también aprovecha para discutir el problema con $\mathrm{D}$. W. Livingston. 
la argumentación del escéptico. Hay ciertos fenómenos (doble visión, ilusiones, alucinaciones, etc.) que parecen convencer a Hume de que el sistema vulgar es inadecuado para interpretar el curso de nuestra experiencia. Hume cree que para explicar adecuadamente estos fenómenos debemos admitir el carácter privado de nuestras percepciones. En el sistema filosófico nuestras percepciones son interpretadas según el canon de los eventos privados y se asume la gramática de lo mental (donde esse est percipi) como gramática general de la percepción. Ahora 'percibir' deja de entenderse según el modelo de 'ver' y pasará a jugar en el discurso del sistema filosófico al modo, por ejemplo, de 'imaginar' ('soñar', 'fantasear', etc.).

Esta primera etapa de la argumentación tiene que ver, como señalamos, con algunos "experimentos" que propone Hume, en los que se produce cierta experiencia anómala: se trata del caso de la doble visión (cfr. T 210-211). Un aspecto que no debemos perder de vista acerca de estos experimentos es el uso explícito que Hume hace en ellos de objetos físicos. En efecto, Hume nos dice que el fenómeno de la doble visión se produce "cuando nos apretamos el ojo con el dedo" y que, de este modo, advertimos que "nuestras percepciones dependen de nuestros órganos sensibles y de la disposición de nuestros nervios y espíritus animales". El carácter fisicalista de este experimento pone en evidencia un rasgo importante de la concepción de Hume acerca de la relación que guardan las argumentaciones escépticas con el sistema vulgar. Sobre este punto volveremos más adelante.

Una vez que hemos admitido la privacidad de cierta clase de percepciones, Hume sostiene que debemos ex-

- Cfr. infra, pp. 141-143. 
tender este carácter a todo fenómeno perceptivo. Inmediatamente encuentra que su explicación le es útil también para dar cuenta de fenómenos tales como el cambio de tamaño en los objetos al alejarse o acercarse a ellos, las alteraciones en su figura, etc. Convencido del mayor poder explicativo del sistema filosofico, proclama la aptitud de éste para construir sobre su base una teoría general de la percepción con rigor científico. Podemos pensar que esta exigencia se apoya en una consideración metodológica típica de la filosofía de Hume: ${ }^{5}$

... cuando mediante un claro experimento hemos descubierto las causas o efectos de un fenómeno, extendemos inmediatamente nuestra observación a todo fenómeno de la misma clase, sin esperar esa repetición constante de la que se derivó la idea primera de esa relación ( $T$ 173-174).

La segunda etapa de la argumentación escéptica consiste en señalar que, una vez que hemos admitido el carácter privado de nuestras percepciones, no hay salida hacia el mundo exterior. En este sentido, Hume sostiene a) que no podemos inferir a partir de nuestras percepciones la existencia de objetos "exteriores" y b) que, en verdad, ni siquiera tenemos derecho a postularlos.

Respecto del primer punto, Hume señala que i) la única manera que tenemos de inferir la existencia de alguna cosa es por medio de una inferencia causal; pero ii) la inferencia causal establece una relación entre percepciones y no entre percepciones y objetos (recordemos que ahora 'percepciones' es tomado en el sentido del sistema filosófico y, dado el carácter privado de nuestra experiencia que asume éste, el punto es casi trivial); en

5 Eate es un punto que ha sido augerido por $A$. Pavcovic. Véase su 'Hume' Argument for the Dependent Existence of Perceptions: An Alternative Reading", en Mind XCI, 1082, pp. 590-591. 
consecuencia, iii) no hay modo de inferir la existencia de objetos (cfr. T 212).

Con respecto al segundo punto, el argumento básico es el siguiente: postular objetos no es otra cosa más que postular un nuevo grupo de percepciones, ya que siendo nuestras percepciones lo único dado a los sentidos, no tenemos idea alguna de algo distinto de éstas (cfr. T 218). De modo que hay dos posibilidades: o bien no concebimos en verdad tales objetos, o bien volvemos al punto de partida.

La filosofía antigua se encuentra en la primera situación (T I IV 3). ¿De qué hablan los filósofos antiguos cuando hablan acerca de sustancias y cualidades ocultas? En cambio, la filosofía moderna nos ofrece un desenlace del segundo tipo (T I IV 4) al creer poder privilegiar ciertas cualidades en los objetos que no dependen de nuestros sentidos para su existencia. Se supone que estas cualidades privilegiadas son la extensión y la solidez. Pero, como vimos, Hume no asiente a la idea de que pueda ser sostenida la existencia pública de algunas de nuestras percepciones a costa de la privacidad de otras:

Si los colores, sonidos, sabores y olores no son sino percepciones, ninguna cosa que podemos concebir posee existencia real, continus $e$ independiente... (T 228).

La forma más breve de expresar la crítica de Hume es, creo, la siguiente: extensión y solidez son cualidades relacionales de nuestras percepciones. No podemos concebir algo extenso sino como un compuesto de partes coloreadas o sólidas. Habiendo excluido previamente los colores de nuestro repertorio de cualidades objetivas, queda por ver qué ocurre con la solidez. Pero la solidez, a su vez, no es sino la idea de dos cuerpos que no pueden interpenetrarse. ¿Qué diremos ahora de esos cuerpos?, 
¿que son extensos? Giramos en torno a un círculo vicioso ( $T$ 228-229).

Así, el filósofo de intenciones constructivas recorre junto al escéptico un primer tramo en el que lo "ayuda" a mostrar que el acontecer de nuestra experiencia sensorial no puede ser interpretado según el modelo de los objetos públicos del sistema vulgar. Pero el filosofo constructivo trata de conciliar su sistema en el que toda experiencia sensorial es un acontecer privado con la creencia en los objetos del sentido común. El escéptico, en cambio, le señala que ha emprendido un camino sin retorno.

Resulta claro que Hume considera que el escéptico argumenta en forma irreprochable. Su estrategia frente a la argumentación escéptica no consiste, por consiguiente, en tratar de refutarla, sino en tratar de neutralizar el poder destructivo de estos argumentos. Un párrafo significativo, en este sentido, es el siguiente:

Si no estuviéramos persuadidos de antemano de que nuestras percepciones constituyen nuestros únicos objetos y de que continúan existiendo aun cuando no se manifiestan a nuestros sentidos, nunea habriamos llegado a pensar que nuestras pereepeiones son diferentes a nuestros objetos y que sólo éstos conservan una existencia continua ( $\mathrm{T} 211$, el subrayado es mío).

El término 'percepción' es usado aquí en dos sentidos bien diferenciados. En un sentido, nuestras percepciones "constituyen nuestros únicos objetos" y continúan existiendo aun cuando no las percibimos. Esta es, como vimos, la tesis del sistema vulgar. Pero, en otro sentido, nuestras percepciones son tomadas como "diferentes a nuestros objetos" y dejan de existir cuando dejamos de percibirlas. Esta es la tesis correspondiente al sistema filosófico. 
Ahora bien, lo que Hume nos dice es que el discurso del sistema vulgar acerca de objetos públicos, en el que nuestras percepciones son tomadas por tales objetos, constituye el lenguaje ordinario acerca de percepciones y está presupuesto por aquel en el que se atribuye a nuestras percepciones el carácter de eventos privados. La posibilidad misma de un lenguaje acerca de percepciones en el sentido del sistema filosófico, radica en el hecho de encontrarse éste montado sobre un marco conceptual de objetos públicos. Coherentemente, Hume afirma que el sistema filosofico

deberá derivar toda su autoridad de la hipótesis vulgar, ya que no tiene autoridad original de suyo ( $T 213$ ).

Hay aún otro aspecto importante. Cuando Hume declara que resulta inútil una investigación orientada a determinar si hay o no cuerpos, una de las razones que da es que

Este es un punto que debemos dar por supuesto en todos nuestros razonamientos (T 187).

A este respecto, conviene tener en cuenta que Hume considera que el sistema vulgar es consistente en el sentido lógico del término (cfr. T 207-208). Son algunos "experimentos" los que muestran su falsedad. Como vimos, Hume considera que algunas experiencias muestran evidencia empírica en contra del sistema vulgar. De modo que ahora el punto es el siguiente: mostrar evidencia empírica supone estar instalados en un marco conceptual de objetos públicos. ${ }^{6}$ En consecuencia, no podemos mostrar evidencia empírica en contra del sistema vulgar sin, al mismo tiempo, presuponerlo. La

- Eate ea un punto que ha aido señalado por D. W. Livingaton. Vease D. W. Livingaton \& J. T. King (ed.), Heme, Revaluation, Nueva York, Fordham Univeraity Preas, 1976, p. 217. 
existencia de los objetos del sistema vulgar es, luego, "un punto que debemos dar por supuesto en todos nuestros razonamientos", aun en aquellos que tratan de probar su falsedad.

Como vimos, la argumentación escéptica comienza con el rechazo del sistema vulgar y su remplazo por el filośfico. Sin embargo, estas observaciones nos advierten acerca del tipo de error que cometen tanto los filósofos como los escépticos: creen haber destruido el sistema vulgar cuando aún no han salido de él.

Podríamos pensar que estas observaciones aclaran uno de los elementos de la tensión que señalamos al comienzo de este trabajo, pero a costa de oscurecer el otro. En efecto, ahora podemos entender mejor la observación de Hume acerca de la inutilidad de inquirir sobre si hay o no cuerpos. Pero si Hume dispone en su teoría de razones de orden lógico para descalificar a este tipo de empresa, no se entiende por qué afirma, de todos modos, que el sistema vulgar es falso.

Parecería ahora que Hume dispone de una vía de escape que le permitiría evadir el inquietante efecto de los argumentos escépticos; una vía, por otra parte, bastante frecuentada - con diferentes variantes - en la filosofía contemporánea. Me refiero a aquella estrategia que consiste en poner fuera de juego a la argumentación escéptica denunciando su carácter de deudora respecto a la creencia del sentido común.

Para comprender la posición que asume Hume respecto de este aspecto, resultará conveniente remitirnos a la sección del Tratado titulada "Del escepticismo con respecto a la razón" (T I IV 1), ya que ahí se plantea una cuestión exactamente paralela en torno a las argumentaciones escépticas que intentan, mediante razonamientos, destruir la razón. Frente a este problema 
Hume emplea una metáfora plena en consecuencias interesantes.

Hume compara la razón con un rey que dicta reglas y normas. Sus enemigos (los escépticos), al utilizar estas reglas (las reglas de la lógica, de la argumentación) en su contra, consiguen un "privilegio real" que toma su fuerza de la autoridad de la cual deriva. Pero al debilitarse esta autoridad, se debilita la fuerza que sus enemigos toman prestada de ella, hasta que el poder de ambos se extingue (cfr. T 186-187).

Podemos describir esta situación del siguiente modo: I) cuando el sistema de la razón es verdadero, los argumentos escépticos logran establecer su conclusión (la autoridad del rey respalda la argumentación escéptica); II) si los argumentos escépticos logran establecer su conclusión, el sistema de la razón no es verdadero; III) siendo el sistema de la razón falso, los argumentos escépticos no logran establecer su conclusión (ya que carecen de autoridad propia).

Ahora, siguiendo el paralelo establecido, remplacemos 'sistema de la razón' por 'sistema vulgar' y volvamos a nuestro tema principal. Podemos pensar que Hume sostiene tres tesis que corresponden, cada una de ellas, a la secuencia anterior, a saber:

(1) Si el sistema vulgar es verdadero, los argumentos escépticos logran establecer su conclusión;

(2) si los argumentos escépticos logran establecer su conclusión, el sistema vulgar es falso;

(3) si el sistema vulgar es falso, los argumentos escépticos no logran establecer su conclusión.

Ahora Hume se encuentra en condiciones de establecer a partir de (1) y (2) 
(4) si el sistema vulgar es verdadero, entonces el sistema vulgar es falso,

de donde se obtiene

(5) el sistema vulgar es falso.

Aunque a partir de (3) y (5) también se obtiene

(6) los argumentos escépticos no logran establecer su conclusión,

la falsedad del sistema vulgar ha sido ahora probada mediante un nuevo argumento cuyas premisas - (1) y (2) - ya no son deudoras del sistema vulgar. En efecto, se trata de una especie de meta-argumento acerca de la relación entre el sistema vulgar y la argumentación escéptica. Sin embargo, de ninguna manera esto alcanza para modificar la situación de privilegio del sistema vulgar. Sigue siendo cierto que, aunque probemos su falsedad, no podemos avanzar un solo paso más. No podemos construir un nuevo sistema que remplace al sistema vulgar. No hay otro sistema. El sistema vulgar es falso, pero es el único sistema de la experiencia.?

7 Valionas eugerencias y observaciones criticas de Margarita Costa, Mark Platts y Raúl Orayen me permitieron mejorar una version anterior de eate trabajo. 